RESEARCH NOTE

\title{
OBSERVATIONS ON BABESIOSOMA MARIAE (APICOMPLEXA: DACTYLOSOMATIDAE) FROM THE OKAVANGO DELTA, BOTSWANA
}

\author{
Nico J. Smit ${ }^{1}$, Jo G. Van As ${ }^{2}$ and Angela J. Davies ${ }^{1}$ \\ ${ }^{1}$ School of Life Sciences, Faculty of Science, Kingston University, Penrhyn Road, Kingston upon Thames, Surrey, KT1 2EE, \\ UK; \\ ${ }^{2}$ Department of Zoology and Entomology, University of the Free State, P.O. Box 339, Bloemfontein, 9300, South Africa
}

In 1991, six dactylosomatids of the genus Babesiosoma Jakowska et Nigrelli, 1956 were listed from fishes (Barta J. 1991: Adv. Parasitol. 30: 1-37), although three of these species were subsequently assigned to the genus Haemohormidium Henry, 1910 (see Siddall M.E., Desser S.S., Measures L.N. 1994: J. Parasitol. 80: 1018-1025). The three fish dactylosomatids from Barta's list that remained were Babesiosoma mariae (Hoare, 1930), Babesiosoma tetragonis Becker et Katz, 1965 and Babesiosoma hannesi (Paperna, 1981). Later, another dactylosomatid, Babesiosoma bettencourti (França, 1908), was added to those known from fishes (Cruz C., Davies A.J. 1998: J. Fish Dis. 21: 443-448), and it was concluded that $B$. mariae and $B$. hannesi are synonymous (Negm-Eldin M.M. 1998: Dtsch. Tierärztl. Wochenschr. 105: 367-374).

This research note reports on a dactylosomatid found in Botswana during a two-year study of the parasites of freshwater fishes of the Okavango Delta system. Initial observations suggest that the parasite is $B$. mariae.

Fishes $(\mathrm{n}=119)$ of 26 species in 17 genera were collected in 2000 and 2001 by gill nets or with rod and line. They were captured in large, temporary, lagoons adjacent to the main stream of the Okavango River in the panhandle region of the Delta. Fishes were brought alive to a field laboratory where they were measured (total length), identified (Skelton P. 2000: A Complete Guide to the Freshwater Fishes of Southern Africa. Struik Publishers, Cape Town, 395 pp.) and kept in aerated aquaria containing fresh, river water. Heart blood smears were fixed in absolute methanol, stained with phosphate-buffered Giemsa ( $\mathrm{pH}$ 6.8) and screened for blood parasites with a $\times 100$ objective on a Zeiss Axioskop 20 photomicroscope. Microscopic images were captured by digital camera (Nikon DN100), stored on computer disks and then parasites were measured with an Eclipse Net (Nikon) image analysis package, calibrated to a stage micrometer.

Only one specimen of all fishes examined (1/119), a thinface largemouth tilapia, Serranochromis angusticeps (Boulenger, 1907), measuring $312 \mathrm{~mm}$ long, contained an intraerythrocytic apicomplexan. Parasites were found only in mature erythrocytes and host cells appeared largely unaffected by the apicomplexan, except for displacement of some host cell nuclei. Intensity of infection was $<1 / 10000$ erythrocytes.

Late trophozoites / young meronts, meronts yielding merozoites and gamonts were recognised (Fig. 1 A-J). Late trophozoites / young meronts (Fig. 1 A-C) occurred in pairs or singly and were elongate or oval. They were largely nonstained, except peripherally, where they stained blue. Their nuclei were not clearly defined. Image analysis showed that these stages measured $3.78 \pm 0.85(2.21-4.98) \times 2.41 \pm 0.54$ $(1.63-3.54) \mu \mathrm{m}(\mathrm{n}=20)$.

Meronts in early division (Fig. $1 \mathrm{D}$ ) were broadly rectangular, with chromatin distributed to the four corners of the parasite body, forming a tetranucleate structure. These stages were largely non-stained, except for the nuclear material that stained deep purple. Late meronts were characteristically cruciform, producing four merozoites (Fig. 1 E). Meronts measured $5.56 \pm 0.31(5.16-5.99) \times 3.39 \pm 0.62(2.68-4.81)$ $\mu \mathrm{m}(\mathrm{n}=10)$ along their greater and shorter axes, respectively.

Gamonts (Fig. 1 F-J) of three kinds were recognised, namely immature, curved mature, and broad mature forms. Only two immature gamonts were seen (Fig. $1 \mathrm{~F}$ ), and these were broadly elongate with one end slightly narrower than the other. Cytoplasm was stained pale blue and the nucleus was difficult to discern, but appeared to lie nearer the narrower end of the parasite body. These stages measured 4.72-5.13 $\times 2.95-$ $3.25 \mu \mathrm{m}(\mathrm{n}=2)$.

More mature gamonts appeared in two morphologically distinct types. A less common form was curved, with a blunt and a more pointed end, and at least two large vacuoles. A prominent nucleus, with chromatin appearing in characteristic dense deep-staining blocks, lay nearer the blunt end (Fig. $1 \mathrm{G}$, $\mathrm{H})$. This form measured $6.20-6.49 \times 2.36-2.67 \mu \mathrm{m}$, with the nucleus of approximately $4.70 \times 2.40 \mu \mathrm{m}(\mathrm{n}=5)$. The majority of gamonts were much broader with two large, distinct vacuoles, especially near the ends of the parasite body, which were rather rounded (Fig. 1 I, J). Pink-staining nuclear material occupied more than half of the body of this stage, and peripheral deep-staining granules were present, associated with the nuclear material. Remaining cytoplasm stained pale blue. These broad gamonts measured $7.15 \pm 0.64$ (5.95-7.91) $\times 3.91 \pm 0.75(2.47-5.07) \mu \mathrm{m}(\mathrm{n}=25)$ and the nucleus $3.84 \pm$ $0.59(2.08-4.76) \times 3.15 \pm 0.67(1.98-4.14) \mu \mathrm{m}(\mathrm{n}=25)$.

The parasite reported from the Okavango Delta clearly produces four intraerythrocytic merozoites from cruciform meronts and is therefore a dactylosomatid of the genus Babesiosoma. This represents the first record of such an apicomplexan from fishes in Botswana, and a first report from S. angusticeps. These observations are remarkable because of the seasonal character of the Okavango Delta water-course and the temporary nature of its lagoons. To our knowledge, 


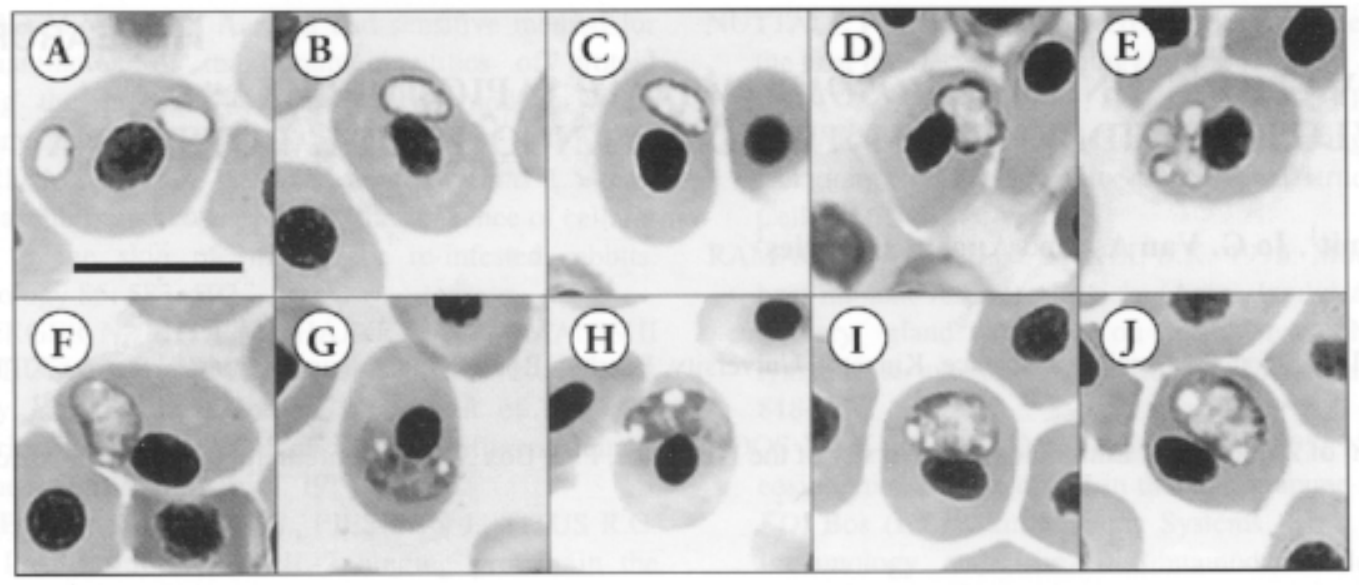

Fig. 1. Giemsa-stained erythrocytes from Serranochromis angusticeps with Babesiosoma mariae. A-C - host erythrocytes with paired or single late trophozoites / young meronts; $\mathbf{D}$ - meront in early division; $\mathbf{E}$ - cruciform meront with four merozoites; $\mathbf{F}$ immature gamont; $\mathbf{G}, \mathbf{H}$ - curved mature gamonts; I, J - broad mature gamonts. Scale bar: $10 \mu \mathrm{m}$ for A-J.

only one other haematozoan, a trypanosome, has been reported from fishes of this changeable freshwater environment (Smit N.J., Davies A.J., Van As J.G. 2000: Bull. Eur. Assoc. Fish Pathol. 20: 116-119).

The parasite recorded here appears to be $B$. mariae. Development stages of this parasite that are morphologically close to ours have been reported previously, but from fishes in Uganda and Egypt (Hoare C.A. 1930: Ann. Trop. Med. Parasitol. 24: 241-248; Baker J.R. 1960: Parasitology 50: 515-526; Negm-Eldin 1998, op. cit.). Although we have the advantage of having measured our parasites using imageanalysis equipment, our late trophozites / young meronts fall within the size ranges quoted by Hoare for trophozoites of the type species $(3.8-5.7 \times 1.9-5.0 \mu \mathrm{m})$ and our meronts are similar to those recorded by this author and by Baker. However, we were not able to recognise the three stages of merogony observed in experimental infections of $B$. mariae (Negm-Eldin 1998, op. cit.).

It has also been noted from experimental infections, that macro- and microgamonts of $B$. mariae cannot be distinguished because of great variability in their shape and staining properties (Negm-Eldin 1998, op. cit.). However, although curved gamonts in Okavango material were marginally shorter than Hoare's microgamonts $(6.6-8.5 \times 1.9-3.5 \mu \mathrm{m})$ and broad gamonts were slightly longer than his macrogamonts (5.7-6.6 $\times 3.8-5.7 \mu \mathrm{m}$ ), our gamonts otherwise closely resembled those described for B. mariae from Uganda (Hoare 1930, op. cit.; Baker 1960, op. cit.). Furthermore, we are not able to report on stages that might exist in an invertebrate host, since no likely vectors, such as leeches, were observed in the current study.
It is difficult to be certain that $B$. mariae is the same dactylosomatid (B. hannesi) reported from mullets in the Swartkops estuary, South Africa (Paperna I. 1981: J. Protozool. 28: 486-491), despite a recent claim that they are synonymous (Negm-Eldin 1998, op. cit.). The early stages of the two parasites are somewhat similar, but the elongated, slender progamont of $B$. hannesi (see Paperna 1981, op. cit.) appears to have no equivalent in $B$. mariae. Furthermore, gamonts of $B$. hannesi, seen only rarely by Paperna, were variable in size, but generally small (mean size $4.4 \pm 0.6 \times 1.3$ $\pm 0.3 \mu \mathrm{m}$ ) and appeared to lack the features (see Paperna 1981, op. cit.) of those of B. mariae. These differences, in gamont morphology and size, do suggest that the two species might not be identical.

Reports of B. mariae in Uganda and Egypt have been noted above (Hoare 1930, op. cit.; Baker 1960, op. cit.; Negm-Eldin 1998, op. cit.), but this species has also been observed from the South African province previously known as Transvaal (Paperna I. 1996: Parasites, Infections and Diseases of Fishes in Africa. An Update. CIFA Technical Paper 31, FAO, Rome, 220 pp.). This distribution, and its presence in Botswana, suggests that Negm-Eldin was correct, and the dactylosomatid demonstrates low specificity among fish hosts and is widespread across Africa (Negm-Eldin 1998, op. cit). This further implies the existence of ancient fish host-parasite relationships, stemming from a time when many freshwater systems across Africa may have been linked.

Acknowledgements. We are grateful to the Debswana Diamond Company and Land Rover South Africa for sponsoring this work in the Okavango Delta. 